\title{
PAZ SOCIAL: LIBERTAD DE EMPRESA EN COLOMBIA FRENTE A LA EVOLUCIÓN DE LAS PERSONAS JURÍDICAS EN MÉXICO
}

\author{
Iván Humberto Galvis Macías ${ }^{1}$ \\ Ángel Torres Hernández ${ }^{2}$ \\ Onésimo Antonio Fabela Serrano ${ }^{3}$
}

\section{Resumen}

La actividad empresarial en Colombia y - ipor qué no decirlo? - en la mayor parte de los Estados del mundo, constituye un elemento esencial para la generación de desarrollo económico y de prosperidad social. La importante labor asumida por el empresario mercantil en todas las economías modernas debe partir, en cada caso particular, de un reconocimiento económico (obtención de ganancias) que no se obtiene de otra manera distinta a la de producir o comercializar los bienes o servicios derivados de determinada actividad, en condiciones de calidad, buen precio y fidelización de la clientela, cuestiones que en sí mismas solo pueden alcanzar los efectos esperados si el empresario ejecuta su actividad en condiciones de competencia (supuesto general de las economías de mercado) y bajo la posibilidad de ejercer su libertad económica. Sin embargo, este reconocimiento económico no se obtendría sin la institucionalización de un sistema de

$1 \quad$ Abogado egresado de la Universidad Santo Tomás Seccional Tunja, con estudios de economía de la Universidad Pedagógica y Tecnológica de Colombia, Especialista en Derecho Constitucional de la Universidad Nacional de Colombia, Especialista en Contratación Estatal (Trabajo de Grado Laureado) de la Universidad Santo Tomás Seccional Tunja, Magíster en Derecho con énfasis en Derecho Económico de la Universidad Externado de Colombia, investigador y docente universitario en programas de pregrado y posgrado.

2 Magíster en Derecho. Especialista en Derecho Tributario y en Gerencia de la Hacienda Pública Abogado y Contador Público. Docente Investigación de la Corporación Antonio José de Sucre. Email: angel_torres@corposucre.edu.co

3 Maestro en Derecho penal de la Universidad de Durando, México. Licenciado en Derecho de la Universidad Nacional Autónoma de México. UNAM. Docente Investigador del Centro Universitario Allende. Email: onefabela@hotmail.com 
garantías jurídicas que le permitan al empresario ejercer su actividad con libertad y, de la misma manera, que protejan el objeto de su empresa de irrupciones o barreras injustificadas que a la postre le impidan obtener su utilidad. El legislador al tener en sus manos, uno de los fines más altos del derecho, la búsqueda constante de la paz social, mediante la promulgación de leyes justas, debe dejar de lado, cualquier interés personal o mezquino que le inclinen, a favorecer a una persona o a un determinado grupo de personas. Su interés final debe centrarse en buscar la paz como estado de tranquilidad social, no solamente de la persona en lo individual, sino también de las personas jurídicas o morales, a través de normas, que ayuden a fortalecer la vida armónica y la tranquilidad social es por esta razón que en este artículo plantea la evolución de las personas jurídicas, la crisis y retos que se deben asumir para consolidar la tan anhelada Paz, a las personas Jurídicas de índole Mercantil, por la gran importancia que conllevan en toda sociedad moderna. Ya que no solo juegan un papel económico preponderante, sino también político y social entre otros rubros y por tanto, su regulación requiere adecuarlas a las necesidades imperantes en el entorno, para que sean un factor de desarrollo y sobre todo que estén encaminadas a la consecución de la paz social.

Palabras clave: Libertad económica, Mercado, Empresa.

\section{Abstract}

Business activity in Colombia and - why not say it? - in most of the world's states, constitutes an essential element for the generation of economic development and social prosperity. The important work assumed by the mercantile businessman in all modern economies must start, in each particular case, from an economic recognition (obtaining profits) that is not obtained in any other way than that of producing or commercializing the goods or services derived from a certain activity, in conditions of quality, good price and loyalty of the clientele, issues that in themselves can only reach the expected effects if the businessman carries out his activity in conditions of competition (general supposition of market economies) and under the possibility of exercising his economic freedom. However, this economic recognition would not be obtained without the institutionalization of a system of legal guarantees that allow the entrepreneur to carry out his activity freely and, in the same way, that protect the object of his 
company from unjustified breakthroughs or barriers that in the end prevent him from obtaining his utility.

KeyWords: Economic Freedom, Market, Enterprise.

\section{Introducción}

La libertad de empresa se constituye en el epicentro del desarrollo y la ejecución de actividades económicas y - con ello - de la generación de empresarios y empresas mercantiles.

Al ser categórica la importancia de este derecho en los ordenamientos jurídicos modernos, se requiere realizar un estudio de la naturaleza jurídica que la caracteriza, de manera particular en el ordenamiento jurídico colombiano, para identificar su alcance y trascendencia en el desarrollo de las relaciones económicas y el aporte que puede brindar a la construcción del desarrollo económico.

El objetivo aquí propuesto se desarrollará través de metodología inductiva en la que i) se describirá una breve definición de lo que el ordenamiento jurídico colombiano entiende por actividad empresarial o empresa mercantil, ii) se desarrollará un examen de la importancia que comporta el derecho a la libertad de empresa en el modelojurídico-económico colombiano, y finalmente iii) se formulará un análisis de la naturaleza jurídica de este derecho en el contexto constitucional colombiano.

\section{El empresario colombiano: una aproximación a su concepto en el contexto jurídico mercantil}

La revisión en torno a la naturaleza jurídica de la libertad de empresa en el ordenamiento jurídico colombiano debe partir, como definición obvia y necesaria, de lo que las instituciones jurídicas entienden por empresario, y de la función que éste desempeña en el desarrollo de las relaciones económicas de una sociedad, sin que por ello se pretenda definir - como se hará en el segundo aparte del presente escrito - el papel que el modelo jurídico-económico le ha otorgado a quien ejecuta libremente su actividad económica con el propósito de generar utilidad y de propiciar beneficios a los demás agentes que, con él, concurren a un mismo mercado. 
Paz social: libertad de empresa en Colombia frente a la evolución de las personas jurídicas en México

En tal sentido, es el Código de Comercio Colombiano en su artículo 25, la prescripción normativa que define la actividad empresarial y que establece sus principales características, dotándolas de relevancia jurídica, Así como lo explica Baena (2013, p. 23):

El empresario mercantil no solamente es aquella persona jurídica constituida para la ejecución de una actividad económica que genere utilidad a sus socios, sino que también corresponde a aquellas personas naturales que - en nombre propio o a través de interpuesta persona o apoderado desarrollan una actividad económica de producción o mediación de bienes y servicios, cumpliendo con las características de publicidad, profesionalismo, uniformidad y reiteración.

Tal concepción del empresario mercantil ata su naturaleza a la propia definición de comerciante que establece el Código de Comercio en su artículo 10, al disponer que: "son comerciantes las personas que profesionalmente se ocupan de las actividades que la ley considera mercantiles. La calidad de comerciante se adquiere, aunque la actividad mercantil se ejerza por medio de apoderado, intermediario o interpuesta persona."

Adicionalmente, Narváez (1997) reconoce la calidad de empresario a aquellas personas que, sin reconocerse jurídicamente como comerciantes, ejecutan una de aquellas actividades que la ley considera como mercantiles, pues define al empresario o comerciante como todas aquellas “(...) personas naturales y jurídicas que tienen la calidad de empresarios mercantiles, y también quienes, sin ostentar esta calidad, realicen accidental u ocasionalmente negocios en operaciones que la ley reputa de naturaleza mercantil.” (p.131).

A partir de tal definición es preciso aclarar que la categoría de empresario mercantil o comerciante no es equiparable en ninguna de sus características a quien ocasionalmente ha ejercido una de las actividades que la ley considera mercantiles, pues - desde nuestra posición - no es lo mismo ejecutar una actividad económica con el carácter profesional y habitual con el que la ejercen quienes - a la luz de la legislación - son considerados comerciantes, que desarrollar una actividad ocasional que deviene en mercantil por disposición legal, pues en el primero de los casos todos los actos del comerciante que se deriven de su actividad mercantil serán regulados por las disposiciones de la legislación comercial, por su propia vocación, 
en tanto que en el segundo solo aquellos actos que sean considerados por la ley comercial como mercantiles acudirán a la regulación del Código de Comercio, mientras que los demás (la generalidad) se regularán por las disposiciones del Código Civil, pues aquel no tiene vocación de desarrollar profesionalmente una actividad mercantil.

De esta manera, como lo reconoce Córdoba (2014), no es posible equiparar las acciones de un empresario mercantil frente a aquellas que ejecuta ocasionalmente un sujeto de derechos no comerciante, pues, aunque las dos se regulen por el derecho mercantil, las relaciones obligacionales del primero siempre estarán dirigidas por la regulación comercial, en tanto que las del segundo solo lo serán cuando se subsuman en algunos de los actos considerados por la ley comercial como mercantiles, de allí que:

La idea de Derecho comercial como área jurídica dedicada a la regulación de la empresa, y por tanto identificado como derecho de la empresa, no tuvo mucha acogida (...) porque fundamentalmente existen actos mercantiles de naturaleza ocasional independientes de cualquier relación con la empresa. (p. 108)

Con todo lo anterior, para establecer una caracterización adecuada de lo que en el ordenamiento jurídico colombiano se entiende por empresario mercantil, se acude a los aportes de Baena, quien aclara que:

El empresario se caracteriza por dos aspectos fundamentales, a saber: por un lado, porque es él quien decide su creación, toma la iniciativa al respecto y porque, salvo excepciones en las que otros lo realizan por él, asume su organización y dirección. Por otro lado, porque al empresario le son imputables, desde el punto de vista jurídico, todas las relaciones en su nombre establecidas con terceros para la explotación adecuada de la empresa y porque, desde el punto de vista económico, es él quien soporta el riesgo derivado del ejercicio de su actividad económica; es decir que su patrimonio está destinado especialmente al cumplimiento de las obligaciones que contraiga en desarrollo de su actividad, por constituir prenda general de sus acreedores. Dentro del ordenamiento jurídico el empresario tiene, entonces, un estatus 
Paz social: libertad de empresa en Colombia frente a la evolución de las personas jurídicas en México

especial derivado de la actividad que desarrolla y del modo como la efectúa. (2013, p. 23)

De la anterior proposición se pueden generar algunos comentarios que, sin lugar a dudas, aportan aspectos relevantes para la cualificación de la empresa mercantil en Colombia, entre los que se destacan:

1. la consolidación de la empresa mercantil encuentra su fundamento en una decisión libre y voluntaria del empresario, quien, desde el ejercicio de su autonomía, toma la iniciativa de invertir una parte de su patrimonio o de reunir el patrimonio de otras bajo su riesgo para la ejecución de una actividad económica determinada; de allí que, en el ordenamiento jurídico colombiano, resulte de vital importancia el reconocimiento de la libertad económica y - con ello - de la libre iniciativa privada, aspecto que será abordado en el siguiente acápite de este trabajo.

2. el empresario mercantil asume, desde su inicio, la forma de organización de su actividad, situación denominada por Tirole (2017) comolagobernanzaempresarial, pues:Elnúcleodelagestión de una empresa es su gobernanza, en otras palabras, los que ejercen el control de la empresa y toman las decisiones más importantes: gestión de recursos humanos, investigación y desarrollo, decisiones estratégicas, fusiones-adquisiciones, tarificación y mercadotecnia, gestión de riesgos, asuntos reglamentarios, etcétera. (p.195)

3. el carácter distintivo entre el empresario mercantil y quien ejecuta actos de comercio ocasionales, radica - además del carácter habitual y reiterado de su actividad económica - en la destinación de su patrimonio al cumplimiento de las obligaciones que contraiga en el ejercicio de tal actividad, asumiendo el riesgo de la misma.

Desde esta perspectiva, el concepto de empresario integra una caracterización en el campo de lo jurídico, pero también una cualificación en el aspecto económico, que ha de desarrollarse en el contexto de la libertad, pues como lo reconoce Ariño (2003):

Detrás de cada empresa hay siempre una persona que pone en juego su patrimonio u obtiene de otras personas un capital a riesgo para llevar a cabo una idea (...) El empresario es el hombre capaz de reunir, de poner juntos todos esos medios para obtener un resultado - unos productos o servicios - 
que ofrece al mercado. Así, una empresa, persona física o jurídica, es un centro final de imputación de responsabilidades, y lo que distingue al empresario del mánager o directivo por él nombrado es que aquel está dispuesto a cubrir con su patrimonio (o con el capital a riesgo que ha podido reunir de otras personas) aquellas responsabilidades económicas. Para llevar a cabo esta labor creadora, el empresario requiere libertad. (p. 257)

\section{La libertad de empresa en el ordenamiento jurídico Colombia. Comen- tarios desde su relevancia en el modelo constitucional económico}

Al requerir libertad para el desarrollo de su actividad económica, el empresario mercantil - ya sea persona natural o jurídica - requiere también de un marco jurídico de protección que le garantice el ejercicio de esa libertad y con ello la posibilidad de participar sin restricciones en las diversas relaciones económicas que se pueden celebrar al interior de las dinámicas de producción, comercialización y consumo de bienes y servicios, propias de un mercado determinado.

Este marco jurídico de protección fue asumido en el ordenamiento jurídico colombiano, a partir de expedición de la Constitución Política de 1991 - y con ello de la denominada Constitución Económica - con la institucionalización de un modelo jurídico-económico cuyo fin principal radica en el reconocimiento efectivo de las libertades económicas de los individuos, frente a las cuales el Estado asume un deber de garantía, pero a su vez se instituye como el ente regulador que permite el reconocimiento de estos derechos ante las denominadas fallas del mercado.

La obligación del Estado de propiciar la garantía efectiva de las libertades económicas encuentra su más evidente reconocimiento - sin desconocer que estas también encuentran solidez a partir del contenido y alcance de v.gr. el derecho de propiedad (art. 60, 64, C.P.), la libertad de elección de profesión u oficio (art. 26 C.P.), la libertad de asociación (art. 38 C.P.), entre otros derechos de orden constitucional - en la disposición contenida en el artículo 333 de la Constitución, que se constituye como el pilar fundamental de la libertad económica y de los derechos a través de los cuales se desarrolla, como son: la libertad de empresa y la libre competencia económica.

De otro lado, asumiendo las realidades económicas experimentadas en el mundo en el último cuarto del siglo XX - en el que la consolidación del 
Paz social: libertad de empresa en Colombia frente a la evolución de las personas jurídicas en México

modelo económico neoliberal emerge e impregna a las grandes economías del mundo (Harvey, 2007, p. 6).- la Constitución Económica dotó al aparato estatal de un vasto catálogo de funciones económicas, entre las que se encuentra la dirección general de la economía; la intervención del Estado - por mandato de la ley - en la explotación de los recursos naturales, el uso del suelo, la producción, distribución, utilización y consumo de bienes, y en los servicios públicos y privados; la racionalización de la economía para propiciar el mejoramiento de la calidad de vida de los ciudadanos; la intervención en la economía para procurar el pleno empleo de los recursos; entre otras tantas Art.334. CN.

Con todo lo anterior, surge en el ordenamiento jurídico colombiano un modelo constitucional-económico en el que el ejercicio de la libre iniciativa privada-a través del reconocimiento de los derechos a la libertad de empresa y a la libre competencia económica - se convierte en el epicentro de las relaciones económicas y se considera la principal herramienta para propiciar el desarrollo económico, garantizándose con ello el funcionamiento de una clara y evidente economía de mercado, pero que al mismo tiempo otorga al Estado la facultad de intervención - a través de múltiples instrumentos cuando la eficiencia perseguida por la economía de mercado no se consolida, y a cambio de ello se experimentan las denominadas fallas del mercado.

Se constituye así en el Estado colombiano el modelo de economía social de mercado, cuyo fundamento normativo - como ya se expresó - encuentra asidero en los artículos 333 y 334 superiores, y que reconoce y garantiza la libertad económica en el marco de la cláusula general del Estado Social de Derecho.

Así - desde una caracterización estrictamente ligada a los postulados propuestos por la teoría económica - se sostiene que las principales características del modelojurídico-económico deeconomía social de mercado convergen en una mixtura entre las más destacadas ideas de la economía clásica - a través de la defensa y garantía de la libertad de mercado - y los postulados de la economía keynesiana bajo los cuales el papel de intervención del Estado constituye el elemento esencial del direccionamiento económico. Sin embargo, esta mixtura de postulados otorga mayor importancia y aplicabilidad a las ideas defendidas por los economistas clásicos, vale decir, a la economía de mercado, dejando al Estado el papel de interventor en ausencia de la eficiencia económica perseguida por tal libertad. 
De esta manera puede afirmarse - aunque tal apreciación genere controversia entre quienes defienden a ultranza el principio de neutralidad económica de la Constitución - que el modelo económico constitucional de economía social de mercado asume como propios los postulados del modelo económico neoliberal, pues, como se ha descrito en breve, propende por el reconocimiento de la libertad de mercado como elemento fundamental del sistema económico, pero a su vez faculta la intervención del Estado en ausencia de la eficiencia económica que debe generar un mercado sin restricciones.

Esta economía social de mercado ha de entenderse entonces “(...) [como] una economía de mercado basada en la libertad e iniciativa privada, que admite ciertas intervenciones del Estado (red de seguridad para garantizar una minima cobertura y servicios a todos los ciudadanos) complementarias y compatibles con aquella.” (Ariño, 2003, p. 177).

En este orden de ideas, el modelo jurídico-económico instituido en la Carta Política de 1991, reconoce la importancia del empresario en las relaciones económicas y el aporte que este representa a la construcción del desarrollo económico de la sociedad, a tal punto que el reconocimiento de la libertad empresarial encuentra garantía y protección desde el ámbito constitucional.

La libertad económica se convierte entonces en un derecho de orden constitucional que - al tenor de lo expuesto por la Corte Constitucional Colombiana - “(...) corresponde a una facultad que tiene toda persona de realizar actividades de carácter económico, según sus preferencias o habilidades, con miras a crear, mantener o incrementar su patrimonio (...)" (Sentencia T-425 de 1992), o lo que es lo mismo, corresponde a la facultad que tiene toda persona de convertirse en empresario mercantil bajo los postulados de la libertad.

Sinembargo, ladenominación delibertadeconómicaenelordenamiento jurídico colombiano, ha de corresponder a un principio integrador de la Constitución Económica, cuyo desarrollo se consolida a través del reconocimiento de dos derechos constitucionales: la libertad de empresa y la libertad de competencia, aunque en diversas ocasiones la doctrina y la jurisprudencia constitucional utilicen indistintamente los conceptos de libertad económica y libertad de empresa como sinónimos. 
De esta manera, el denominado derecho a la libertad de empresa, a través del cual toda persona tiene la facultad de convertirse en empresario mercantil, se reconoce en nuestro ordenamiento como un derecho que ostenta una doble dimensión: en primer lugar, la dimensión objetiva, que corresponde según (Correa, 2009):

(...) la obligación del Estado y del legislador [que] en su regulación debe encaminarse a asegurar la eficacia de la libre empresa como derecho constitucional fundamental real (...)"(y en segundo lugar, la dimensión subjetiva, conforme a la cual este derecho corresponde a "(...) un conjunto de elementos que facultan a su titular para actuar de una determinada manera, para esperar determinados comportamientos por parte del Estado y de los particulares y que le asignan ciertas garantías para hacer efectivas todas esas posiciones jurídicas. (p. 273)

Con todo lo anterior, la doctrina y la jurisprudencia han reconocido unos núcleos esenciales del derecho a la libertad de empresa, que-conforme a los postulados de la teoría de los derechos - no pueden ser anulados por el legislador, y que en nuestro ordenamiento jurídico corresponden a:

(i) el derecho a un tratamiento igual y no discriminatorio entre empresarios o competidores que se hallan en la misma posición; (ii) el derecho a concurrir al mercado o retirarse; (iii) la libertad de organización y el derecho a que el Estado no interfiera en los asuntos internos de la empresa como la organización empresarial y los métodos de gestión; (iv) el derecho a la libre iniciativa privada; (v) el derecho a la creación de establecimientos de comercio con el cumplimiento de los requisitos que exija la ley; $y$ (vi) el derecho a recibir un beneficio económico razonable. (Sentencia C-197 de 2012).

Analizada entonces la relevancia que ostenta la libertad de empresa en el contexto jurídico-económico del Estado colombiano, procede ahora realizar un estudio acerca de la naturaleza jurídica que éste derecho asume en nuestro ordenamiento jurídico, pues no de otra manera se concluiría el objeto de este trabajo que, en últimas, lo que pretende es esclarecer su naturaleza. 


\section{La naturaleza jurídica de la libertad de empresa en el contexto constitucional colombiano}

Con claridad hemos evidenciado hasta aquí que la libertad de empresa constituye una institución absolutamente necesaria para el ejercicio de las distintas actividades económicas lícitas y para la constitución de la empresa mercantil. Por lo mismo esta libertad es reconocida en el orden constitucional como un auténtico derecho que - además de su relevancia jurídica - ostenta una importancia categórica para la generación de desarrollo económico según las disposiciones del modelo jurídico-económico de economía social de mercado, aplicable en nuestra organización estatal.

Sin embargo, la definición de la libertad de empresa como un derecho constitucional no resulta ser suficiente para esclarecer su naturaleza jurídica, toda vez que, en el ordenamiento constitucional colombiano, existen varias categorías de derechos, todas ellas con unas características específicas, alcances determinados y medios de protección diversos.

Por lo anterior, la definición de la naturaleza jurídica del derecho a la libertad de empresa pretende auscultar la categoría de derecho que aquella representa en el contexto constitucional colombiano, para lo cual se acudirá a un análisis jurisprudencial de distintos pronunciamientos (línea jurisprudencial) en los que la Corte Constitucional Colombiana ha realizado una aproximación a su delimitación.

Este análisis responderá a un interrogante preciso: en el contexto constitucional colombiano ¿es la libertad de empresa un derecho de carácter fundamental o un derecho de contenido estrictamente económico?

Estas dos categorías parten de las posibilidades de elección que la Corte Constitucional ha asumido expresa o tácitamente en el estudio de este derecho.

Otra precisión metodológica que se considera pertinente establecer previo a abordar el asunto de fondo, corresponde a la descripción de la forma de selección de las sentencias que fueron analizadas: todas ellas presentan similitud en la estructura del problema jurídico que resuelven, pues aunque algunas correspondan a un análisis de constitucionalidad concreto y otras a análisis de constitucionalidad abstracto, en todos los casos se estudia la confrontación que generan disposiciones normativas o actuaciones de autoridades públicas con la libertad de empresa, al ejecutarse actos 
Paz social: libertad de empresa en Colombia frente a la evolución de las personas jurídicas en México

o expedirse normas que - en un análisis primario - vulneran el derecho constitucional a la libertad de empresa.

Así, el estudio de la jurisprudencia de la Corte Constitucional ha llevado a identificar tres etapas que se debaten entre, por un lado, el reconocimiento de la iusfundamentalidad del derecho a la libertad de empresa y, por el otro, su carácter estrictamente iuseconómico, como se procede a sintetizar:

\section{Primera Etapa: la libertad de empresa como derecho fundamental}

La Corte Constitucional Colombiana en sentencias T-419 de 1992 y T-425 del mismo año, revisa dos casos de tutela en los que - en el primero - se analiza la actuación de la administración municipal de Envigado, quien solicita de la beneficiaria del remate de un bien dentro de un proceso ejecutivo, el pago de los impuestos de los demás bienes de propiedad de la persona ejecutada, para la expedición de la correspondiente paz y salvo (del bien rematado). Al hacer el análisis de constitucionalidad de los actos de la administración de Envigado, la Corte encuentra que ésta desconoció el principio de libertad económica, pues la ley exige que para la expedición del paz y salvo de un bien este debe contar con el pago del respectivo impuesto predial que genere. Sin embargo, al requerir la administración municipal el pago del impuesto de otros bienes que no eran objeto del remate, transgredió la libertad económica de la beneficiaria del remate y demandante, al exigir un requisito no previsto en la ley para la expedición del paz y salvo, desconociendo la disposición contenida en el inciso primero del artículo 333 de la Constitución. Por esta razón la Corte Constitucional decide confirmar la sentencia objeto de revisión, en la que se decidió tutelar el derecho al debido proceso de la accionante.

En el segundo caso la Corte revisa la acción de tutela interpuesta por dos ciudadanos quienes solicitan se tutele el derecho al trabajo junto con otras reclamaciones, a quienes la Inspección de Policía de Chía les allanó un establecimiento de comercio y les confiscó dos máquinas de videojuegos construidas por ellos, teniendo como fundamento jurídico unos actos administrativos locales que prohibían el ejercicio de esta actividad en locales comerciales que no fuesen dedicados exclusivamente a esta actividad. La Corte Constitucional establece que las limitaciones a la libertad económica son una potestad exclusiva del legislador y por lo mismo declara la inaplicación por inconstitucionalidad de los actos administrativos ejecutados 
por la administración y en su lugar conceder la tutela interpuesta por los demandantes.

En otro caso de singular importancia, la Corte - mediante sentencia SU-182 de 1998 - revisa las tutelas interpuestas por los representantes legales de algunas empresas de telecomunicaciones en el país, quienes solicitan la protección de su derecho a la igualdad frente a la actuación de la Comisión de Regulación de Telecomunicaciones, por cuanto aquella permitió que TELECOM tomara parte en la prestación del servicio de telefonía local, mientras que a ellas les impedía entrar a competir en la prestación del servicio a larga distancia. Frente a tal problema jurídico, la Corte establece que la CRT impuso a las demandantes limitaciones a la libertad de empresa que no fueron establecidas por la ley, por lo que decidió confirmar las decisiones de instancia en las que se tuteló el derecho a la igualdad de los demandantes.

Como se puede evidenciar de los casos analizados, si bien la Corte Constitucional Colombiana reconoció en este periodo - a través de la argumentación dispuesta en la parte motiva de cada una de sus sentencias - la importancia y alcance de la libertad de empresa en sede de revisión de tutela (lo que permite reconocer el carácter fundamental de este derecho), la parte resolutiva de sus providencias no se dirigió a tutelar el derecho fundamental a la libertad de empresa, sino que por el contrario, decidió proteger otros derechos que por expresa disposición constitucional se consideran como fundamentales, lo que a nuestro juicio permite identificar una situación particular: aunque para algunos doctrinantes este periodo se identifique como el escenario de reconocimiento de la iusfundamentalidad de la libertad de empresa, lo cierto es que, aunque la corte sí aborda este derecho en sus respectivos análisis, en sus decisiones no lo tutela como derecho fundamental.

\section{Segunda Etapa: la libertad de empresa como derecho NO fundamental, pero tutelable por conexidad}

En esta segunda etapa constituye un hito la sentencia de unificación SU-157 de 1999, en la que la Corte Constitucional revisa las tutelas de dos ciudadanos a quienes las entidades financieras colombianas les terminaron unilateralmente sus productos y servicios financieros por haber aparecido en la denominada Lista Clinton. Frente a este caso particular la Corte argumenta que el derecho a la personalidad jurídica constituye una garantía fundamental para ser titular de derechos y obligaciones, 
como consecuencia de lo anterior se encuentra absolutamente prohibida toda sanción que elimine definitivamente la posibilidad de acceder a las actividades económicas lícitas. En este orden de ideas la Corte Consideró que la decisión de las entidades financieras de terminar unilateralmente los productos y servicios de los demandantes, además de violar el debido proceso y el derecho a la igualdad, cercenó el derecho a la personalidad jurídica de los mismos y con ello sus libertades económicas. En tal argumentación expresó el carácter no fundamental de la libertad de empresa pero su posibilidad de serlo vía conexidad:

Enestecontexto, sibienlaslibertadeseconómicasnoson derechos fundamentales per se y que, además, pueden ser limitados ampliamente por el Legislador, no es posible restringirlos arbitrariamente ni es factible impedir el ejercicio, en igualdad de condiciones, de todas las personas que se encuentren en condiciones fácticamente similares (C.P. art. 13 y 333). Por consiguiente, es viable predicar la ius fundamentalidad de estos derechos cuando se encuentren en conexidad con un derecho fundamental, esto es, cuando su ejercicio sea el instrumento para hacer efectivo un derecho fundamental. Por lo tanto, es claro que en el presente asunto el derecho a la iniciativa privada de los accionantes se encuentra directa e inescindiblemente ligado con dos derechos fundamentales: el reconocimiento a la personalidad jurídica y el de la igualdad.(Sentencia SU-157 de 1999)

De lo anterior se colige que en este análisis la corte reconoce la no ius fundamentalidad del derecho a la libertad de empresa, pero lo considera tutelable por conexidad, situación que hubiese podido reconocer en los casos analizados en la primera etapa, en los que no reconoce la libertad de empresa como derecho fundamental, pero sí ata su reconocimiento por vía de tutela a la protección de otros derechos de esta naturaleza, pues, como lo reconoce Correa (2009):

(...) en lo que se refiere a la libertad de empresa, la Corte no ha empleado formalmente la conexidad con derechos tutelables más que en un caso, pues en los demás (...) se habría podido decir lo mismo, pero no se hace, y en su lugar se ha protegido la libertad bajo el nombre de otro derecho o se ha empleado otro argumento causal. (p.320) 


\section{Tercera Etapa: el reconocimiento de la libertad de empresa como derecho estrictamente económico}

Tal vez ésta sea la etapa que mayores aportes brinda a la conclusión de este trabajo. De ella hacen parte las sentencias cuyos aspectos generales se identifican a continuación:

Sentencia C-616 de 2001: estudia la exequibilidad parcial de algunos artículos de la Ley 100 de 1991, mediante los cuales se permite que las empresas prestadoras de servicios de salud E.P.S., puedan prestar el servicio a sus afiliados a través de sus propias I.P.S., y en particular si aquellas normas violan la libertad de empresa en razón al trato preferencial que podrían tener las I.P.S. de propiedad de las E.P.S. en detrimento de otras que conservan su independencia. La Corte resuelve la exequibilidad de las normas demandadas con fundamento en que la garantía de la libertad de empresa impide que se obstaculice o prohíba a las E.P.S. la prestación directa del servicio asistencial a través de sus propias I.P.S.

Sentencia C-615 de 2002: estudia la exequibilidad parcial de algunos artículos de la Ley 715 de 2001 que establecen la prohibición de que las instituciones públicas y privadas de salud realicen inversiones que no estén contenidas en el plan bienal de inversiones expedido por las secretarias de salud de los entes territoriales, y en caso de que lo hagan se imponga la sanción de no poder contratar con recursos del Sistema General de Participaciones, particularmente resuelve la Corte si tal obligación y sanción cercenan la libertad económica de los prestadores de salud. El Tribunal resuelve la inexequibilidad de las normas acusadas, por cuanto resulta acorde a la carta que las instituciones públicas deban cumplir las metas de los planes bienales de inversión, pero en relación con las instituciones privadas, prohibirles que inviertan por fuera de estos planes anula su derecho a la libertad económica.

Sentencia C-219 de 2015: estudia la inexequibilidad parcial de algunos artículos del Decreto Ley 019 de 2012 que otorgan a un particular (Organismo Nacional de Acreditación de Colombia - ONAC) la facultad de decidir sobre la posibilidad de que otro particular (entidades de certificación) desarrolle una actividad económica. La corte resuelve la constitucionalidad de las normas demandadas argumentando que las entidades de certificación cumplen funciones dirigidas a garantizar la seguridad jurídica en las relaciones comerciales, por lo tanto, las restricciones que se impongan a 
las mismas ameritan un juicio de constitucionalidad débil, pues se trata de asuntos económicos y relacionados con la intervención del Estado en los servicios públicos, y el mecanismo es idóneo para el fin propuesto.

Sentencia C-284 de 2017: estudia la exequibilidad parcial del artículo 98 de la ley 30 de 1992 que impone a las Entidades de Educación Superior privadas constituirse como entidades sin ánimo de lucro, particularmente si esta disposición restringe la libertad de empresa y competencia. Resuelve la Corte la exequibilidad de la norma demandada reconociendo que la norma de intervención no está anulando la libertad de empresa, sino que simplemente está determinando unos requisitos para el ejercicio del derecho.

Las anteriores sentencias encuentran dos aspectos en común: i) todas reconocen de manera expresa que el derecho a la libertad de empresa no es un derecho fundamental, sin siquiera mencionar que pueda llegar a serlo a través de la figura de la conexidad; y ii) reconocen que la libertad económica no es un derecho absoluto que admite restricciones atendiendo a criterios de razonabilidad y proporcionalidad.

Por lo anterior, la Corte ha dispuesto que toda intervención que el legislador realice a derechos de orden constitucional debe atender a los parámetros del denominado test integrado de razonabilidad, que según lo dispuestoporel TribunalConstitucionalobedeceaunametodologíadeanálisis de constitucionalidad que integra el test de proporcionalidad aplicado en los tribunales constitucionales europeos y los escrutinios de constitucionalidad aplicados en el sistema constitucional norteamerica(Sentencia C-093 de 2001).

Con lo anterior, y de acuerdo a lo dispuesto en la Sentencia C-015 de 2014, el test integrado de razonabilidad se debe aplicar de la siguiente manera: 
Tabla 1

Test integrado de razonabilidad

\begin{tabular}{ccc}
\hline ÁMBITOS DE APLICACIÓN & ESCRUTINIO & $\begin{array}{c}\text { SUBPRINCIPIOS DE } \\
\text { PROPORCIONALIDAD } \\
\text { APLICABLES }\end{array}$ \\
\hline $\begin{array}{c}\text { Materias económicas, } \\
\text { tributarias o de política } \\
\text { Internacional }\end{array}$ & Débil. & Idoneidad. \\
$\begin{array}{c}\text { Derechos no fundamentales o } \\
\text { libre competencia. } \\
\begin{array}{c}\text { Discriminación, debilidad } \\
\text { manifiesta, minorías, derechos } \\
\text { fundamentales. }\end{array}\end{array}$ & Intermedio & Idoneidad y necesidad. \\
\hline
\end{tabular}

Fuente: Creación Propia de los autores.

\section{Conclusión}

Con lo examinado anteriormente se puede concluir que el derecho a la libertad de empresa en el ordenamiento jurídico colombiano no ha ostentado la naturaleza de derecho fundamental en sentido estricto, ni siquiera en la primera fase jurisprudencial aquí analizada, en la que se le reconoció como fundamental pero atado al reconocimiento de otro derecho que sí pertenece a dicha categoría. Por el contrario, el mayor acercamiento de la libertad de empresa a la iusfundamentalidad ha sido por la vía de la conexidad.

Por esto, es dable concluir que el derecho a la libertad de empresa en Colombia ostenta la naturaleza jurídica de un derecho económico, conclusión que se soporta en dos premisas fundamentales: i) desde el año 1999 la Corte Constitucional ha reconocido expresamente que este derecho no es fundamental per se; en jurisprudencia posterior y hasta la actualidad ni siquiera ha reconocido su iusfundamentalidad por vía de conexidad, y ii) en el análisis de proporcionalidad y razonabilidad exigido para la intervención de este derecho, la jurisprudencia ha aplicado - en la mayoría de los casos - un escrutinio débil de la intervención, en el que verifica que la medida sea idónea para alcanzar el fin constitucionalmente deseado y que con ella no se anule por completo el derecho intervenido, toda vez que en 
Paz social: libertad de empresa en Colombia frente a la evolución de las personas jurídicas en México

materia económica, por disposición constitucional, el legislador cuenta con una amplia facultad de configuración legislativa.

\section{Referencias}

Baena, L. G. (2013). Lecciones de Derecho Mercantil. 2ª Ed. Bogotá: Colombia. Universidad Externado de Colombia.

Constitución Política de Colombia. [Const.]. Julio 7 de 1991 (Colombia). Córdoba, P. A. (2014). El derecho de sociedades y el gobierno de la sociedad anónima: el interés social, órganos, accionistas y administradores. Bogotá: Colombia. Universidad Externado de Colombia.

Correa, M. (2009). La libertad de empresa en el Estado Social de Derecho. Bogotá, Colombia: Universidad Externado de Colombia.

Corte Constitucional Colombiana. Sala Plena. Sentencia T-419 (M.P. Simón Rodríguez Rodríguez; Junio, 17, 1992).

Corte Constitucional Colombiana. Sala Plena. Sentencia T-425 (M.P. Ciro Angarita Barón; Junio, 24, 1992).

Corte Constitucional Colombiana. Sala Plena. Sentencia SU-182 (M.P. Carlos Gaviria Díaz y José Gregorio Hernández Galindo; Mayo, 06, 1998).

Corte Constitucional Colombiana. Sala Plena. Sentencia SU-157 (M.P. Alejandro Martínez Caballero; Marzo, 10, 1999).

Corte Constitucional Colombiana. Sala Plena. Sentencia C-093 (M.P. Rodrigo Escobar Gil; Enero, 31, 2001).

Corte Constitucional Colombiana. Sala Plena. Sentencia C-616 (M.P. Rodrigo Escobar Gil; Junio, 13, 2001).

Corte Constitucional Colombiana. Sala Plena. Sentencia C-865 (M.P. Rodrigo Escobar Gil; Marzo, 14, 2004).

Corte Constitucional Colombiana. Sala Plena. Sentencia C-197 (M.P. Rodrigo Escobar Gil; Septiembre, 07, 2012).

Corte Constitucional Colombiana. Sala Plena. Sentencia C-015 (M.P. Mauricio González Cuervo; Enero 23, 2014).

Corte Constitucional Colombiana. Sala Plena. Sentencia C-219 (M.P. Mauricio González Cuervo; Abril, 22, 2015). 
Decreto 410 de 1971. Por el cual se expide el Código de Comercio. (Junio 17 de 1971. D.O. 33.339).

Harvey, D. (2007). Breve historia del neoliberalismo. Madrid, España: Ediciones Akal S.A.

Narváez, J. I. (1997). Derecho Mercantil ColombiaParte General. 8ª Ed. Bogotá: Colombia. Legis S.A.

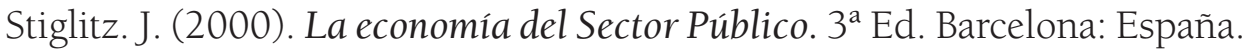
Antoni Bosch, Editor.

Tirole, J. (2017). La economía del bien común. ¿Qué ha sido de la búsqueda del bien común? ¿En qué medida la economía puede contribuir a su realización? Bogotá: Colombia. Taurus.

Uprimny, R. \& Rodriguez, C. (2004-2005). Constitución y modelo económico en Colombia: hacia una discusión productiva entre economía y derecho. (Trabajo preliminar). Bogotá, Colombia: Dejusticia. Recuperado de: https://cdn.dejusticia.org/wp-content/uploads/2017/04/ fi_name_recurso_775.pdf 